Article

\title{
Environmental, Human Health and Socio-Economic Effects of Cement Powders: The Multicriteria Analysis as Decisional Methodology
}

\author{
Laura Moretti $^{1, *}$, Paola Di Mascio ${ }^{1}$ and Simona Bellagamba ${ }^{2}$ \\ 1 Department of Civil, Construction and Environmental Engineering, Sapienza University of Rome, \\ 00184 Rome, Italy; paola.dimascio@uniroma1.it \\ 2 Consulting Engineer, Rome, Italy; simonabellagamba@libero.it \\ * Correspondence: laura.moretti@uniroma1.it; Tel.: +39-06-44585114 \\ Academic Editor: Jason K. Levy \\ Received: 12 May 2017; Accepted: 10 June 2017; Published: 16 June 2017
}

\begin{abstract}
The attention to sustainability-related issues has grown fast in recent decades. The experience gained with these themes reveals the importance of considering this topic in the construction industry, which represents an important sector throughout the world. This work consists on conducting a multicriteria analysis of four cement powders, with the objective of calculating and analysing the environmental, human health and socio-economic effects of their production processes. The economic, technical, environmental and safety performances of the examined powders result from official, both internal and public, documents prepared by the producers. The Analytic Hierarchy Process permitted to consider several indicators (i.e., environmental, human health related and socio-economic parameters) and to conduct comprehensive and unbiased analyses which gave the best, most sustainable cement powder. As assumed in this study, the contribution of each considered parameter to the overall sustainability has a different incidence, therefore the procedure could be used to support on-going sustainability efforts under different conditions. The results also prove that it is not appropriate to regard only one parameter to identify the 'best' cement powder, but several impact categories should be considered and analysed if there is an interest for pursuing different, often conflicting interests.
\end{abstract}

Keywords: cement; multicriteria analysis; life cycle assessment; construction industry

\section{Introduction}

The current European Union (EU) regulatory framework concerning the contracting authorities encourages policies inspired by social needs and environmental principles, which contribute to the achievement of sustainable development. Protection and preservation of the natural environment are characterized by three important stages:

1. The transition from development concepts exclusively linked to economic growth, to ones which balance economic, environmental and social issues [1];

2. The definition of environmental protection as an EU constitutional principle [2]: in the last years policies focused on promoting and encouraging the production of more environmentally friendly goods have been adopted;

3. The introduction of the concept of "life cycle" of a product $[3,4]$ and the introduction of "green public procurement" (GPP) [5], applicable to all types of public bids, with the aim of guiding public administrations towards purchasing goods and services less detrimental to the environment [6]. 
For this purpose, the European Member States have adopted National Action Plans (PANs) [7] to implement GPP procedures in their bids. In Italy, Minimum or Rewarding Environmental Criteria, (MEC or REC), respectively, have been defined: the first ones permit to get into a tender, the second ones allow the competitors to have an additional score. The Italian approach pursues not only environmental but also human health-related objectives: the damage-oriented approach considers damage to human health, ecosystem quality and depletion of resources. This holistic approach is closely related to the growing interest and diffusion of environmental labels which provides guidance on developing criteria, compliance, systems, and operating procedures for awarding sustainability targets [8]. The ISO 14040 series [9-13] sets out three types of labeling scheme: type I is elaborated by a third party, type II is elaborated by the producer, and type III which is based on a full life-cycle assessment, elaborated by the producer and certified by a third party. All three consist of the sustainability performances of the examined product [14], considering its consequences on the environment and human health. However, there are not yet recognized or accredited methodologies to issue such labels: often the approach is subjective and it does not allow a comprehensive analysis. The most frequent adopted methods are based on the interrelation matrices, graphs and check lists, and multi-criteria decision theory [15].

Interrelation matrices permit one to identify and assess the interactions of a project with the surrounding environment. The most known method is the Leopold matrix [16], whose elements represent the environmental impact of each task by means of a couple of values (the coefficients of importance and magnitude). It permits one to compare different alternatives, identifying the projects with maximum positive or negative impact. The procedure does not consider the interaction between effects, and does not give criteria to define the importance and magnitude coefficients, therefore it does not ensure reliable results. Graphs (or networks) derive from interrelation matrices, but they do not allow quantitative and comparative analyses. Check lists consist of qualitative environmental, social and economic elements or quantitative reference lists to be considered in the calculation of impacts. The Environmental Evaluation System, known also as the Battelle method [17,18], is the best known. This method does not consider existing uncertainties between objective and subjective values of indicators and their functions. Moreover, it does not consider the possibility of interaction with the community [19] for defining parameters, especially in case of human and social factors. The models based on the "multi-criteria decision" theory permit one to identify the best alternative, to get a ranking of alternatives, to reduce the number of alternatives to be analyzed, and to distinguish between acceptable and not acceptable alternatives. In this context, the Analytic Hierarchy Process (AHP) is particularly suitable when most costs and benefits are intangible, and it is not possible to compare economic data.

This last methodology has been used in the paper, which compares the environmental, human health and social effects [20] of cement, the most used material on the world [21] for structure and infrastructure construction [22-26]. The study considers four powders whose "environmental" performances have been certified by mean Environmental Product Declarations (EPD), which are type III labels [27]. Workers' safety and health, and economic data derive from internal documents produced by the companies. The results permit to compare the sustainability of the cements, and identifying the strengths and weaknesses of the examined powders.

The methodology herein adopted could be efficiently used and modified to analyze other products or services: it is a versatile and unbiased tool to achieve the sustainable policies encouraged by the European Community legislature.

\section{Materials and Methods}

The authors considered four gray cements prepared by four different Italian companies, which are not named for reasons of confidentiality. All cements guarantee $32.5 \mathrm{MPa}$ of 28-day characteristic cubic compressive resistance $\left(R_{c k}\right)$. All powders are Portland-pozzolana cements, defined as CEM II according to [28]: they have $65-89 \%$ of clinker, $21-35 \%$ of natural pozzolana, and $0-5 \%$ of other constituents. Although each clinker content is not known by the authors, however the powders are comparable because they represent specific, detailed and homogeneous chemical and mechanical 
characteristics. As regard to as the environmental and social criteria, the study considers the impact categories listed in Table 1: their values refer to the production of $1 \mathrm{Mg}$ of cement. According to the standard EN 15804 [29], these categories describe environmental impacts, resource use, and waste categories related to a production. They are therefore representative of environmental and human health consequences of a manufacturing process.

Table 1. Impact categories examined in the study.

\begin{tabular}{|c|c|c|c|c|c|}
\hline Impact Categories & Unit of Measure & Cement 1 & Cement 2 & Cement 3 & Cement 4 \\
\hline Global Warming Potential, GWP & $\mathrm{kg} \mathrm{CO} 2$ eq. & 737.59 & 664.6 & 785 & 611 \\
\hline Ozone Depletion Potential, ODP & kg CFC-11 eq & $3.39 \times 10^{-5}$ & $3.41 \times 10^{-5}$ & $5.16 \times 10^{-5}$ & $1.00 \times 10^{-5}$ \\
\hline Photochemical Ozone Creation Potential, POCP & $\mathrm{kg} \mathrm{C}_{2} \mathrm{H}_{4} \mathrm{eq}$ & 0.12 & 0.11 & 0.26 & 0.07 \\
\hline Eutrophication Potential, EP & $\mathrm{kg} \mathrm{PO}_{4} \mathrm{eq}$ & 0.45 & 0.43 & 0.28 & 0.18 \\
\hline Non-hazardous Waste, $n H W$ & $\mathrm{~kg}$ & 158 & 188 & 0.053 & 6.11 \\
\hline Hazardous Waste, $H W$ & $\mathrm{~kg}$ & 0.12 & 0.14 & 0.1 & 0.0307 \\
\hline Renewable resources with energy content, $R R E$ & MJ & 199 & 192.77 & 275 & 256 \\
\hline Non-renewable resources with energy content, $n R R E$ & MJ & 7185 & 6799.01 & 6525 & 3080 \\
\hline Electricity, $E$ & $\mathrm{kWh}$ & 189.41 & 183.17 & 132 & 175 \\
\hline Water consumption, $W$ & $\mathrm{~m}^{3}$ & 0.481 & 0.573 & 0.705 & 0.674 \\
\hline
\end{tabular}

As regard to the human health protection criteria, the authors considered the most common risks for construction industry workers [30]: noise, whole body vibrations (WBV), hand-arm vibrations (HAV), exposure to allergizing substances, exposure to $\mathrm{Cr}(\mathrm{VI})$ (hexavalent chromium), and exposure to free crystalline silica (FCS). All values are deduced from the (internal) Document of Risk Evaluation prepared by each company, as required by the Italian standard about the safety of workers [31]. As regard as the content of $\mathrm{Cr}(\mathrm{VI})$, the Italian companies comply with the European Directive 2003/53/CE [32] and doubly test their cements to increase worker safety [33]. As regard to the exposure to FCS, the weekly Permissible Exposure Limit considered in the study is compliant with the American Conference of Governmental Industrial Hygienists standards [34]. Examined risks have been classified according to the standardization proposed by the Italian Ministry of Labour [35].

For the economic issues, the authors considered the unit price of cements, listed on the pricelist of each cement plant (not herein disclosed due to privacy reasons). Table 2 lists the human health and economic data.

Table 2. Human health and economic data examined in the study.

\begin{tabular}{cccccc}
\hline Parameter & Unit of Measure & Cement 1 & Cement 2 & Cement 3 & Cement 4 \\
\hline Exposure to Cr(VI) & - & Not relevant & Not relevant & Low & Not relevant \\
Exposure to FCS & - & Not relevant & Not relevant & Low & Not relevant \\
Exposure to allergising substances & - & Low & Low & Average & Not relevant \\
Noise & $\mathrm{dB}(\mathrm{A})$ & 80 & 80.5 & 82 & 79 \\
WBV & $\mathrm{m} / \mathrm{s}^{2}$ & 0.5 & 0.5 & 0.65 & 0.4 \\
HAV & $\mathrm{m} / \mathrm{s}^{2}$ & 1 & 1 & 1.2 & 1.05 \\
Unit price & $€ / \mathrm{m}^{3}$ & 136 & 148 & 150 & 112 \\
\hline
\end{tabular}

FCS: free crystalline silica; WBV: whole body vibrations, HAV: hand-arm vibrations.

The impact categories listed in Tables 1 and 2 have been considered as decision criteria to choose the most sustainable cement powder by mean the AHP method. It consists of decomposition of decision problem (what is the best, or most sustainable, cement?) into hierarchy of easier sub-problems, each independent from others. Each element of the hierarchy could be referred to any aspect of the decision problem (e.g., both tangible and intangible, measured and estimated variables).

The method is composed of three phases:

1. Hierarchical decomposition, which includes:

- a first level, which represents the overall "goal" of the analysis;

- a final level, which represents the alternatives to be considered; 
- intermediary levels, which represent criteria and subcriteria for evaluating the alternatives (named A1, A2, A3), as represented in Figure 1.

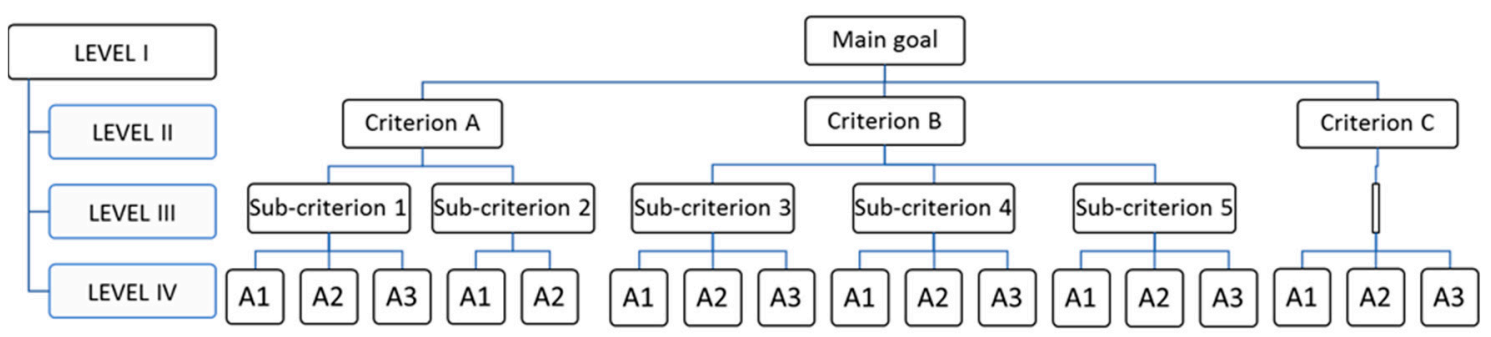

Figure 1. Example of hierarchical decomposition.

Figure 1 represents four levels of analysis. The hierarchical decomposition consists of three criteria (criterion A, B and C) and five sub-criteria (sub-criterion 1 to 5) to be applied to three alternatives.

2. Pairwise comparison: each element of each level is compared to other elements of its level respect to each criterion of the higher level. The decision maker should answer questions such as: "how much is the alternative i preferable with respect to the alternative $\mathrm{j}$ from the point of view of the $\mathrm{k}$ criterion?" or "how much is the criterion 1 most important than the criterion $\mathrm{m}$ with respect to the general objective?" The answer should be quantitative, therefore when it is not possible the relative scale of importance by Saaty [36] could be used. This method determines the relative importance of criteria by mean the pairwise comparison, using the numerical/semantic scale represented in Table 3.

Table 3. Scale of importance by Saaty [36].

\begin{tabular}{ccl}
\hline Intensity of Importance & Definition of Importance & \multicolumn{1}{c}{ Condition } \\
\hline $\mathbf{1}$ & Equal & Both elements contribute equally to the goal \\
\hline $\mathbf{3}$ & Moderate & Experience and judgement moderately favour one of the elements \\
\hline $\mathbf{5}$ & Strong & Experience and judgement strongly favour one element over another \\
\hline $\mathbf{7}$ & Very strong & Judgement very strongly favour one element over another \\
\hline $\mathbf{9}$ & Extreme & $\begin{array}{l}\text { One element is favoured very strongly over another, as confirmed } \\
\text { by evidence }\end{array}$ \\
\hline $\mathbf{2 , 4 , 6 , 8}$ & $\begin{array}{c}\text { Intermediate values between } \\
\text { odd adjacent values }\end{array}$ & Compromise is necessary \\
\hline
\end{tabular}

The scale of importance shown in Table 3 allows the decider composing the matrices pairwise comparisons $(C)$, whose $e_{i j}$ elements means the preference of $i$ with respect to $j$ and the $e_{j i}$ are reciprocal of $e_{i j}$ (Table 4). As consequence of this, such matrices are square and have dimensions equal to the number of variables $\left(O_{i}\right)$ considered elements in the hierarchical level under consideration.

Table 4. Example of matrix $C$.

\begin{tabular}{ccccc}
\hline & $\boldsymbol{O}_{\mathbf{1}}$ & $\boldsymbol{O}_{\mathbf{2}}$ & $\boldsymbol{O}_{\mathbf{3}}$ & $\boldsymbol{O}_{\mathbf{4}}$ \\
\hline$O_{1}$ & 1 & $m_{12}$ & $m_{13}$ & $m_{14}$ \\
$O_{2}$ & $1 / m_{12}$ & 1 & $m_{23}$ & $m_{24}$ \\
$O_{3}$ & $1 / m_{13}$ & $1 / m_{23}$ & 1 & $m_{34}$ \\
$O_{4}$ & $1 / m_{14}$ & $1 / m_{24}$ & $m_{34}$ & 1 \\
\hline
\end{tabular}

For each hierarchical level, the decision maker generates as many pairwise comparison matrices as elements of the upper level. From each of these matrices, elements of the considered hierarchical 
level are ordered respect to each involved criterion of the upper level. A pairwise comparison matrix is consistent if any three elements $e_{i j}, e_{i k}, e_{j k}$ satisfies Equation (1) [37]:

$$
e_{i k}=e_{i j} e_{j k}
$$

3. Hierarchical re-composition: from the vector of preferences of each lower level respect to its upper level, it is possible to obtain the vector of overall ordering vector of alternatives in relation to the goal. In presence of 3-level hierarchy, as represented in Figure 1, ordering vectors are those of alternatives compared to each criterion and those of criteria compared to the goal.

Compared to benefit/cost analyses, the evaluation in the AHP process does not seek to find the "optimum project", but to find a satisfactory solution to several, often intangible, objectives considered in the decisional process. According to the Pareto efficiency, the analysis is based on optimum allocation of available resources [38]. The hierarchical analysis is mathematically more complex than classic multi-criteria analysis [39], but it simplifies the work of decision maker, which responds to simple and same type questions, the pairwise comparisons. Subjective elements, as the choice of the relative importance scale, and the definition of the acceptable threshold inconsistency, are present in the hierarchical analysis and they limit the action of decision maker, but the method ensures an inclusive approach to multi-criteria problems. Indeed, it allows the evaluation of multiple aspects, as happens in construction bids, where legislative, technical, economic and environmental issues should be considered. On other hand, the method is decried as being arbitrary in the assignment of the relative weights and influenced in the result by the number of considered alternatives. As regard as the first weak point, the authors interviewed technicians from different backgrounds, experts in the fields of environment, human health and economy (i.e., data listed in Tables 1 and 2). As regard as the latter weak point, the analysis considers only ten impact categories instead of 26 defined by [29], and limits human health and economic analysis to the most considered variables at international level [40].

\section{Results}

The study focused on the choice of the most sustainable cement powder to be used for cement bound mixtures (e.g., grouts, mortars, concrete). The four cement powders are identified by the nomenclature cement $n$, with $n$ varying from 1 to 4 , and they are produced by different plants numbered according to the cement nomenclature (i.e., cement 1 is produced by plant 1 or company 1 ). The hierarchy defined by the authors involves four level of analysis, as represented in Figure 2:

(1) The main goal, the choice of the best cement powder (level I);

(2) The objectives of (level II):

a. Minimizing environmental interferences,

b. Minimizing negative social-economic aspects,

c. Maximizing health of workers reducing their job risk;

(3) The objectives of (level III):

a. Minimizing impacts on the atmosphere, terrain and water resources (sub-objectives of environment analysis),

b. Minimizing the effects of noise, chemical substances and mechanical vibrations (sub-objectives of workers' health analysis),

c. Minimizing the energy consumption and costs (sub-objectives of socio-economic analysis);

(4) The objectives of (level IV):

a. Minimizing global warming potential $(G W P)$, ozone depletion potential $(O D P)$, and photochemical ozone creation potential ( $P O C P$ ) (sub-objectives of atmosphere analysis), 
b. Minimizing eutrophication potential (EP) (sub-objective of water environment analysis),

c. Minimizing non-hazardous and hazardous waste (sub-objectives of terrain analysis),

d. Minimizing exposure to free crystalline silica, Chromium VI and allergizing substances (sub-objectives of chemical risk analysis for workers),

e. Minimizing exposure to whole body vibrations and hand-arm vibrations (sub-objectives of mechanical risk analysis for workers),

f. Minimizing consumption of renewable resources with energy content, non-renewable resources with energy content, electricity, and water.

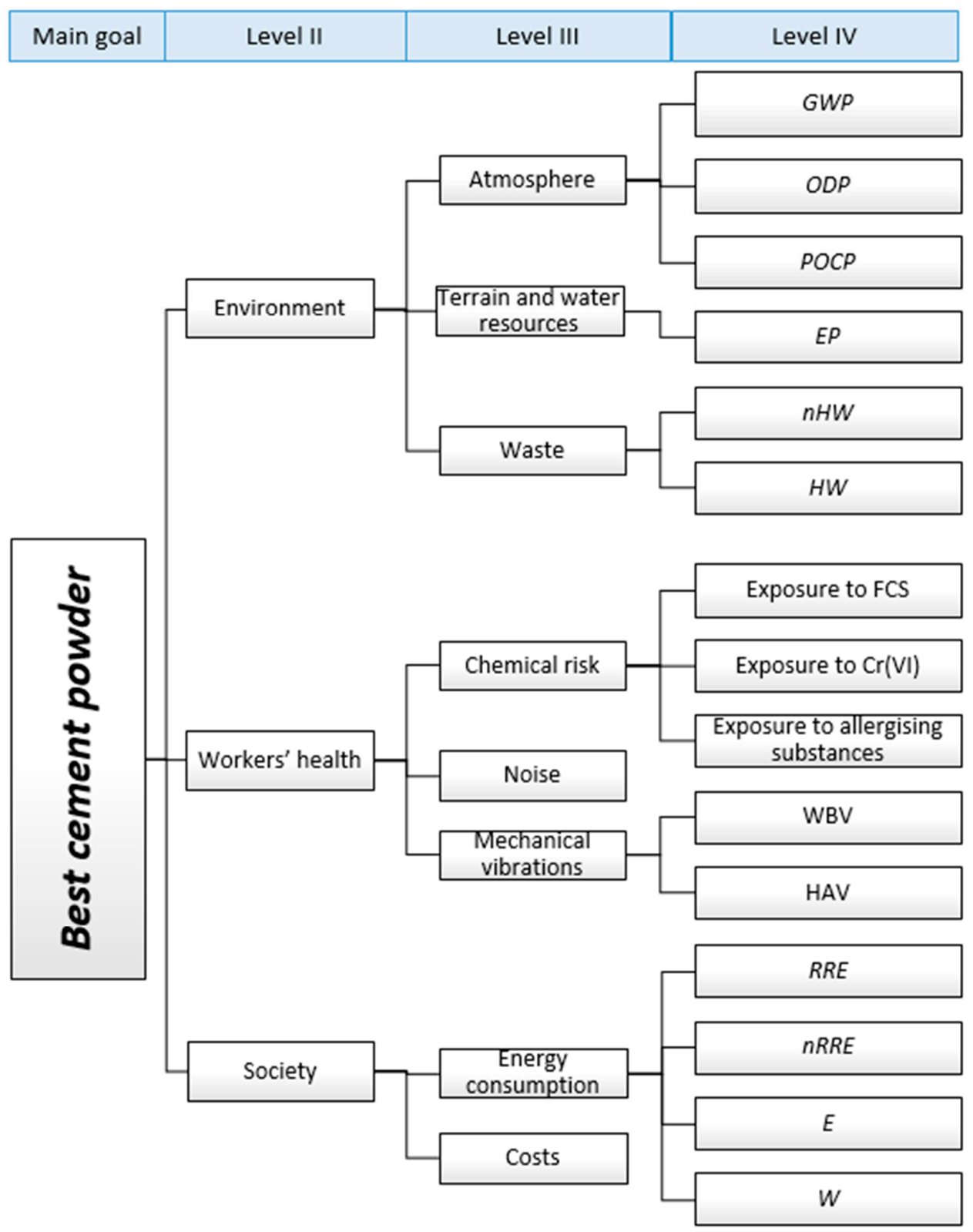

Figure 2. Hierarchical decomposition used for the analysis. GWP: global warming potential; ODP: ozone depletion potential; POPC: photochemical ozone creation potential; EP: Eutrophication potential; $n H W$ : non-hazardous waste; HW: hazardous waste; FCS: free crystalline silica; WBV: whole body vibrations; HAV: hand-arm vibrations; RRE: renewable resources with energy content; $n R R E$ : non-renewable resources with energy content; $E$ : electricity; $W$ : water consumption. 
As regard as the priorities relating to the three criteria of level II, pairwise comparisons gave the results shown in Table 5. Thirty two (32) technicians have participated in the AHP analysis: eight environmental engineers, eight chemical engineers, eight occupational physicians, and eight energy managers. The geometric mean has been used to aggregate individual judgements and obtain pairwise comparison matrices. Values of $c_{i j}$ show little preference for workers' health respect to environment and society, consistently with the main goal of "sustainability".

Table 5. Pairwise comparison matrix for level II (C,II).

\begin{tabular}{cccc}
\hline Level II & Environment & Workers' Health & Society \\
\hline Environment & 1 & 0.5 & 2 \\
Workers' health & 2 & 1 & 2 \\
Society & 0.5 & 0.5 & 1 \\
\hline
\end{tabular}

Each element $c_{i j}$ derives from application of the Saaty method [36]: it represents the importance relationships between each pair of criteria.

Pairwise comparison matrix for level II (C,II) has been normalized. Each element $x_{i j}$ of the normalized pairwise comparison matrix for level II ( $\left.\mathrm{N}_{\text {,II }}\right)$ is obtained by dividing each element $c_{i j}$ by the sum of each column of pairwise comparison matrix (Equation (2)):

$$
x_{i j}=\frac{C_{i j}}{\sum_{j=1}^{n} C_{i j}}
$$

Table 6 represents the normalized pairwise comparison matrix $\left(\mathrm{N}_{\text {,II }}\right)$ for level II.

Table 6. Normalized pairwise comparison matrix for level II ( $\left.\mathrm{N}_{\text {,II }}\right)$.

\begin{tabular}{cccc}
\hline Level II & Environment & Workers' Health & Society \\
\hline Environment & 0.29 & 0.25 & 0.40 \\
Workers' health & 0.57 & 0.50 & 0.40 \\
Society & 0.14 & 0.25 & 0.20 \\
\hline
\end{tabular}

Table 6 allowed the calculation of weights to be related to each criterion of level II. Weights $w_{i j}$ have been obtained by Equation (3):

$$
w_{i j}=\frac{\sum_{j=1}^{m} X_{i j}}{m}
$$

Weight vector of level II ( $\left.\mathrm{W}_{\text {,II }}\right)$ is represented in Table 7.

Table 7. Weight vector for level II ( $\left.\mathrm{W}_{\text {,II }}\right)$.

\begin{tabular}{cc}
\hline Level II & Weights \\
\hline Environment & 0.312 \\
Workers' Health & 0.490 \\
Society & 0.198 \\
\hline
\end{tabular}

The analysis of consistency was composed of three phases:

- Analysis of consistency of each criterion and assessment of consistency vector;

- Measure of consistency by mean consistency index $(C I)$ as deviation or degree of consistency according to Equation (4):

$$
C I=\frac{l_{\max }-n}{n-1}
$$


where $n$ is the size of the pairwise comparison matrix $C$ and $l_{\max }$ is the largest eigenvalue of $C$ when $w$ is the weight vector, $l_{\max }$ satisfies Equation (5):

$$
C \cdot w=l_{\max } \cdot w
$$

- Measure of the ratio consistency (RC) according to Equation (6):

$$
R C=\frac{C I}{R C I}
$$

where $\mathrm{RCI}$ is the Random Consistency Index proposed by Saaty for different size of the comparison matrix (Table 8).

Table 8. Random Consistency Index [36].

\begin{tabular}{ccccccccccc}
\hline $\boldsymbol{R C I}$ & $\mathbf{0}$ & $\mathbf{0}$ & $\mathbf{0 . 5 8}$ & $\mathbf{0 . 9}$ & $\mathbf{1 . 1 2}$ & $\mathbf{1 . 2 4}$ & $\mathbf{1 . 3 2}$ & $\mathbf{1 . 4 1}$ & $\mathbf{1 . 4 5}$ & $\mathbf{1 . 4 9}$ \\
\hline $\boldsymbol{n}$ & 1 & 2 & 3 & 4 & 5 & 6 & 7 & 8 & 9 & 10 \\
\hline \multicolumn{1}{c}{ RCI: random consistency index. }
\end{tabular}

It is acceptable $R C \leq 1$; other values require revision of the subjective judgements.

The analysis of consistency for level II gave the results listed in Table $9\left(l_{\max }\right.$ is 3.05).

Table 9. Consistency analysis for level II.

\begin{tabular}{cc}
\hline $\boldsymbol{C I}$ & 0.03 \\
\hline $\boldsymbol{R C I}$ & 0.58 \\
$\boldsymbol{R} \boldsymbol{C}$ & 0.05 \\
\hline
\end{tabular}

$C I$ : mean consistency index; $R C$ : ratio consistency.

The results listed in Table 9 satisfy the condition proposed by Saaty [36]: the judgements are within the limit of consistency. As regard as the priorities relating to criteria of level III, pairwise comparisons for environment analysis gave the results shown in Table 10.

Table 10. Pairwise comparison matrix for level III, environment analysis (C,IIIe).

\begin{tabular}{cccc}
\hline Level III, Environment & Atmosphere & Waste & Water Environment \\
\hline Atmosphere & 1 & 0.33 & 1 \\
Waste & 3 & 1 & 3 \\
Water environment & 1 & 0.33 & 1 \\
\hline
\end{tabular}

Table 11 shows the normalized pairwise comparison matrix for level III, environment analysis $(\mathrm{N}$, IIII $)$.

Table 11. Normalized pairwise comparison matrix for level III, environment analysis.

\begin{tabular}{cccc}
\hline Level III, Environment & Atmosphere & Waste & Water Environment \\
\hline Atmosphere & 0.20 & 0.20 & 0.20 \\
Waste & 0.60 & 0.60 & 0.60 \\
Water environment & 0.20 & 0.20 & 0.20 \\
\hline
\end{tabular}

Weight vector of level III, environment analysis $\left(\mathrm{W}_{\text {,IIIe }}\right)$ is represented in Table 12. 
Table 12. Weight vector for level III ( $\left.\mathrm{W}_{\text {,IIIe }}\right)$.

\begin{tabular}{cc}
\hline Level III, Environment & Weights \\
\hline Atmosphere & 0.200 \\
Waste & 0.600 \\
Water environment & 0.200 \\
\hline
\end{tabular}

The analysis of consistency of level III, environment analysis gave the results listed in Table 13: they satisfy the condition proposed by Saaty [36] ( $l_{\max }$ is 3$)$.

Table 13. Consistency analysis for level III, environment analysis.

\begin{tabular}{cc}
\hline $\boldsymbol{C I}$ & 0 \\
\hline $\boldsymbol{R C I}$ & 0.58 \\
$\boldsymbol{R C}$ & 0 \\
\hline
\end{tabular}

Similar procedure has been applied to criteria "worker's health" and "socio-economical" aspects. For the first one the results are based on the pairwise comparison matrix for level II, shown below in Table 14.

Table 14. Pairwise comparison matrix for level III, Workers' health analysis (C,IIIW).

\begin{tabular}{cccc}
\hline Level III, Workers' Health & Chemical Risk & Noise & Mechanical Vibrations \\
\hline Chemical risk & 1 & 5 & 6 \\
Noise & 0.2 & 1 & 3 \\
Mechanical vibrations & 0.17 & 0.33 & 1 \\
\hline
\end{tabular}

Weight vector for level III, workers' health analysis is represented in Table 15.

Table 15. Weight vector for level III $\left(\mathrm{W}_{\text {IIIIw }}\right)$.

\begin{tabular}{cc}
\hline Level III, Workers' Health & Weights \\
\hline Chemical risk & 1 \\
Noise & 0.2 \\
Mechanical vibrations & 0.1 \\
\hline
\end{tabular}

As regard as the priorities relating to criteria of level IV, pairwise comparisons for atmosphere analysis gave the results shown in Table 16.

Table 16. Pairwise comparison matrix for level IV, atmosphere analysis (C,IVa).

\begin{tabular}{cccc}
\hline Level IV, Atmosphere & GWP & ODP & POCP \\
\hline GWP & 1 & 0.5 & 2 \\
ODP & 1 & 1 & 0.5 \\
POCP & 0.5 & 2 & 1 \\
\hline
\end{tabular}

Table 17 shows the normalized pairwise comparison matrix for level IV, atmosphere analysis $(\mathrm{N}, \mathrm{IVa})$. 
Table 17. Normalized pairwise comparison matrix for level IV, atmosphere analysis.

\begin{tabular}{cccc}
\hline Level IV, Atmosphere & GWP & ODP & POCP \\
\hline GWP & 0.40 & 0.14 & 0.57 \\
ODP & 0.40 & 0.29 & 0.14 \\
POCP & 0.20 & 0.57 & 0.29 \\
\hline
\end{tabular}

Weight vector of level IV, atmosphere analysis $(\mathrm{W}, \mathrm{IVa})$ is represented in Table 18.

Table 18. Weight vector for level IV ( $\left.\mathrm{W}_{\text {,IVa }}\right)$.

\begin{tabular}{cc}
\hline Level IV, Atmosphere & Weights \\
\hline GWP & 0.371 \\
ODP & 0.276 \\
POCP & 0.352 \\
\hline
\end{tabular}

The analysis of consistency of level IV, atmosphere analysis gave the results listed in Table 19: they satisfy the condition proposed by Saaty [36] ( $l_{\max }$ is 3.11).

Table 19. Consistency analysis for level III, environment analysis.

\begin{tabular}{cc}
\hline $\boldsymbol{C I}$ & 0.06 \\
\hline $\boldsymbol{R C I}$ & 0.58 \\
$\boldsymbol{R C}$ & 0.09 \\
\hline
\end{tabular}

Similar procedure has been applied to sub-criteria waste, water environment, energy.

At the end of the hierarchical analysis involving all sub-criteria, the cements have been compared. Table 20 shows the comparison matrix for environmental sub-criteria GWP.

Table 20. Pairwise comparison matrix for environmental sub-criteria GWP.

\begin{tabular}{ccccc}
\hline GWP & Cement 1 & Cement 2 & Cement 3 & Cement 4 \\
\hline Cement 1 & 1 & 0.33 & 3 & 0.20 \\
Cement 2 & 3 & 1 & 5 & 0.33 \\
Cement 3 & 0.33 & 0.20 & 1 & 0.17 \\
Cement 4 & 5 & 3 & 6 & 1 \\
\hline
\end{tabular}

Table 21 shows the normalized pairwise comparison matrix for environmental sub-criteria GWP.

Table 21. Normalized pairwise comparison matrix for environmental sub-criteria GWP.

\begin{tabular}{ccccc}
\hline GWP & Cement 1 & Cement 2 & Cement 3 & Cement 4 \\
\hline Cement 1 & 0.11 & 0.07 & 0.20 & 0.12 \\
Cement 2 & 0.32 & 0.22 & 0.33 & 0.20 \\
Cement 3 & 0.04 & 0.04 & 0.07 & 0.10 \\
Cement 4 & 0.54 & 0.66 & 0.40 & 0.59 \\
\hline
\end{tabular}

Weight vector of GWP for the examined alternatives is represented in Table 22. 
Table 22. Weight vector of GWP.

\begin{tabular}{cc}
\hline GWP & Weights \\
\hline Cement 1 & 0.125 \\
Cement 2 & 0.268 \\
Cement 3 & 0.061 \\
Cement 4 & 0.546 \\
\hline
\end{tabular}

The analysis of consistency of environmental sub-criterion GWP gave the results listed in Table 23: they satisfy the condition proposed by Saaty [36] ( $l_{\max }$ is 4.15$)$.

Table 23. Consistency analysis for GWP.

\begin{tabular}{cc}
\hline $\boldsymbol{C I}$ & 0.05 \\
\hline $\boldsymbol{R} C \boldsymbol{I}$ & 0.90 \\
$\boldsymbol{R} \boldsymbol{C}$ & 0.08 \\
\hline
\end{tabular}

Similar procedure has been applied to all considered sub-criteria of level IV. Considering the level IV of the criterion "atmosphere", the corresponding sorting matrix of alternatives with respect to considered sub-criteria is composed of the vertical weight vectors calculated for each sub-criterion considered in the level under criterion atmosphere (Table 24).

Table 24. Sorting matrix of alternatives, atmosphere.

\begin{tabular}{cccc}
\hline Level IV & GWP & ODP & POCP \\
\hline Cement 1 & 0.125 & 0.138 & 0.142 \\
Cement 2 & 0.268 & 0.138 & 0.142 \\
Cement 3 & 0.061 & 0.050 & 0.062 \\
Cement 4 & 0.546 & 0.673 & 0.654 \\
\hline
\end{tabular}

Performances of cements respect to atmosphere are calculated by mean the hierarchical re-composition of the analysis. In particular, the sorting matrix of alternatives, atmosphere shown in Table 24 should be multiplied by:

- $\quad$ The sorting vertical vector calculated for level IV, atmosphere (Table 18);

- The weight of atmosphere in the vertical weight vector for level III (Table 15);

- The weight of environment in the vertical weight vector for level II ( $\left.\mathrm{W}_{\text {,II }}\right)$ (Table 7).

The same procedure should be adopted for other environmental criteria of level IV. Figure 3 shows the results.

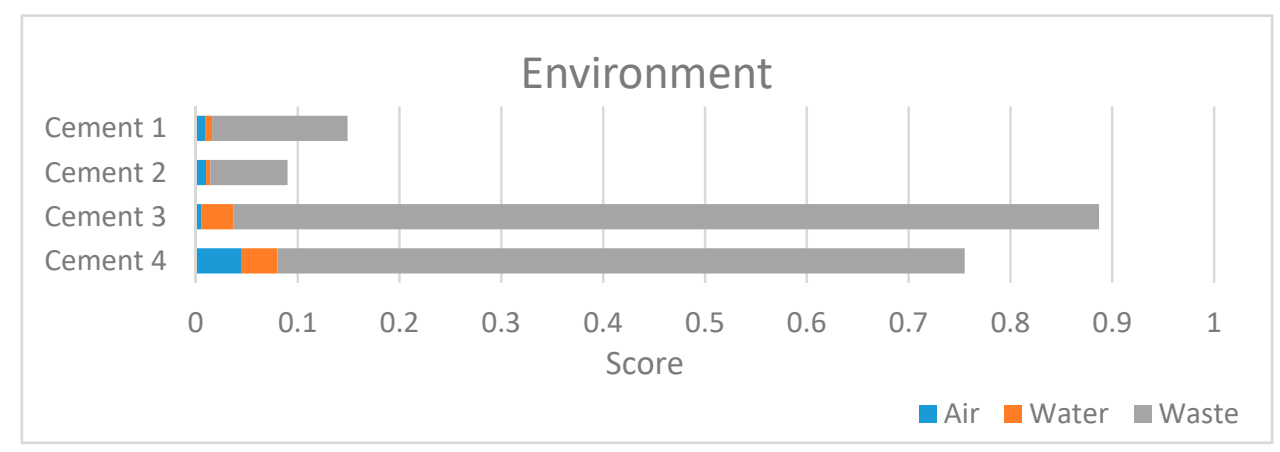

Figure 3. Level II: environmental results. 
Figure 3 highlights the waste production has a relevant role in environmental impact in all examined cements. Waste management is more efficient in plants which produce cement 3 and 4 . The main waste products are paper and cardboard packaging, wooden and plastic packaging, mineral oils, electrical equipment and refractory materials out of order. In order to reduce their impact on the environment and allow their recovery, it is necessary to provide an advanced waste collection. In the Italian cement sector this practice covers $36 \%$ of total solid waste production [41].

Atmosphere emissions are related to implementation of Best Available Techniques (BAT) for cement industry, as reported in the European Reference document for the "Production of Cement, Lime and Magnesium Oxide" [42]. Particularly, the use of secondary fuels or raw materials (e.g., waste or by-products of mechanical and chemical industries) allows an integrated waste management approach, which saves natural and non-renewable resources and permits to recover waste in highly controlled conditions [43]. At this purpose, plant 4 has the best performance in terms of atmospheric emissions as consequence of:

- Applying BAT (dry process kiln with multistage preheating and precalcination-in plant 4-, instead of Lepol kilns which causes higher values of emissions and fuel consumption-in plants 1 to 3 );

- High percentages of caloric substitution by means of alternative fuels (average value $16.3 \%$ for plant 4 , on average $8.2 \%$ for plants 1 to 3 ).

As regard as the water environment, better performances of plant 4 respect to plants 1 to 3 are related to the environmental policies adopted by the company 4 : it has practically zeroed the release of industrial water into the environment replacing open circuit system with closed loop systems.

Figure 4 represents the results obtained about the workers' health.

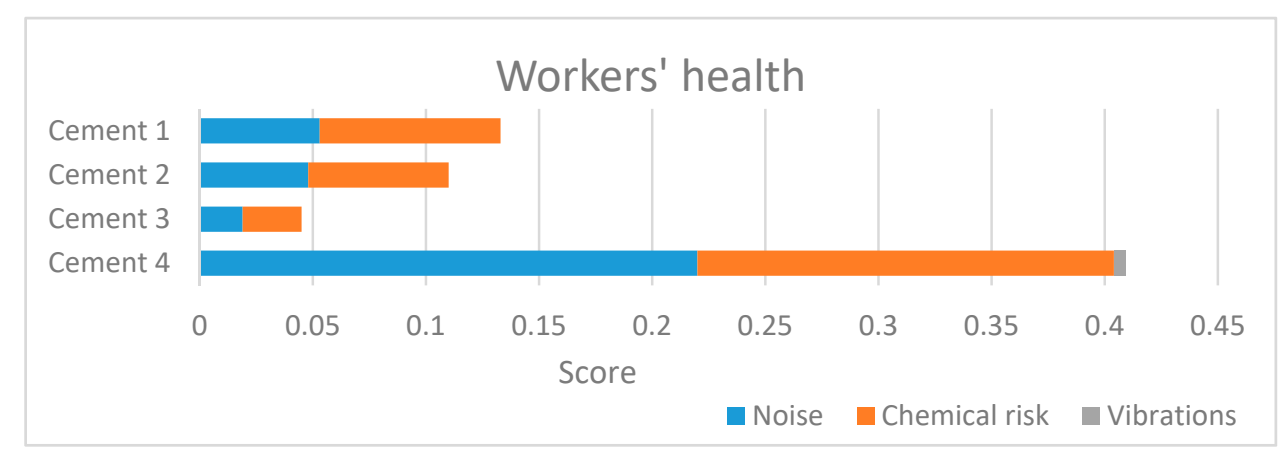

Figure 4. Level II: workers' health results.

The influence of mechanical vibrations (transmitted both to the whole body and to hand/arm) on workers' health has very low importance. The result is justified by the machines park of each company, which belongs to the latest generation [42].

The chemical risk assumes an important role, as expected, since the operators come into contact with substances which significantly affect their health. The purchase of new equipment and the use of additives and chemicals not harmful to human health rewarded company 4 . It is therefore confirmed the need for adopting protective and preventive measures to reduce chemical risks, especially for plant 3, which has the worst workers' health performances. According to Figure 4, the noise in cement plants represents the second factor of risk after the chemical one: mechanical equipment produces high noise, especially if they are not compliant with noise regulations [44]. It is therefore important to quieter equipment and machinery, and use hearing protection to reduce this risk $[45,46]$. Figure 5 represents the results obtained about the socio-economic issues. 


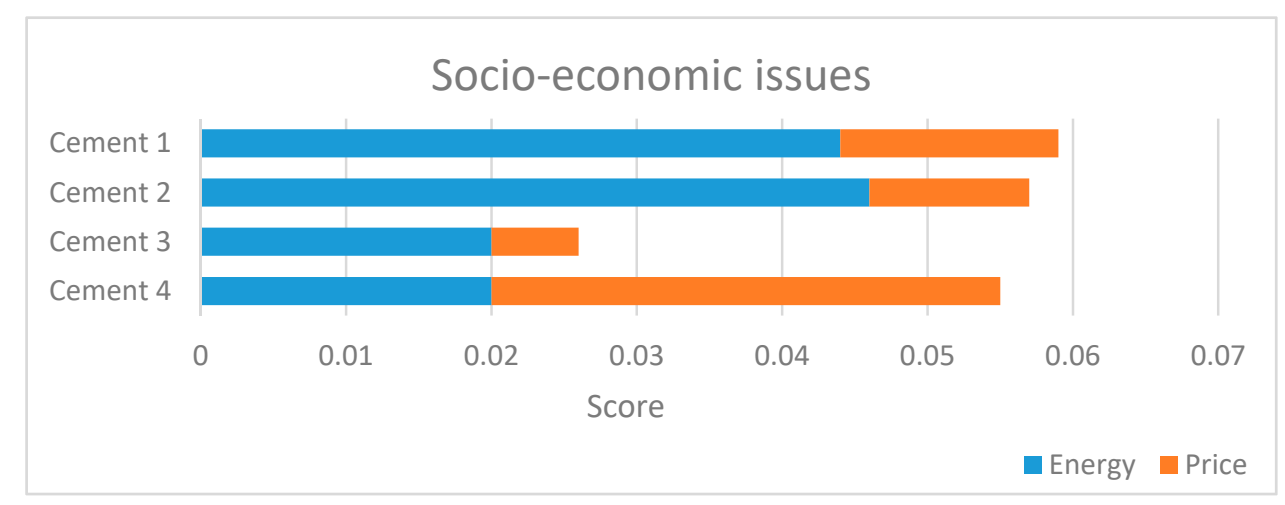

Figure 5. Level II: socio-economic results.

As regard as the energy consumption, the analysis considered water and electricity consumption. Most of the observed differences are related to water consumption, since electricity consumption for cements which have the same $R_{c k}$ is not appreciable [47]. The realization of closed rings circuits permits to substantially reduce water consumption, during the cooling phase [48]. Plant 2 has the best results, also related to the reuse of rainwater in the production cycle, while companies 3 and 4 have the worst performances because they did not implement measures to recycle and reduce water consumption.

As regard as the unit price, cement 4 is the most convenient, the opposite of cement 3 which is the most expensive.

The results shown in Figures from 3 to 5 have been summed for each criterion listed in level I. This procedure allowed the selection of best cement, as represented in Table 25.

Table 25. Contribution of elements of level II to the main goal.

\begin{tabular}{ccccc}
\hline Best Cement & Environment & Workers' Health $^{\prime}$ & Society & Final Results \\
\hline Cement 1 & 0.149 & 0.133 & 0.059 & $\mathbf{0 . 3 4 1}$ \\
Cement 2 & 0.090 & 0.110 & 0.057 & $\mathbf{0 . 2 5 7}$ \\
Cement 3 & 0.887 & 0.045 & 0.026 & $\mathbf{0 . 9 5 8}$ \\
Cement 4 & 0.755 & 0.409 & 0.055 & $\mathbf{1 . 2 2 0}$ \\
\hline
\end{tabular}

Figure 6 graphically represents the final results listed in Table 25. For each cement powder the contribution of each criterion of level I is represented.

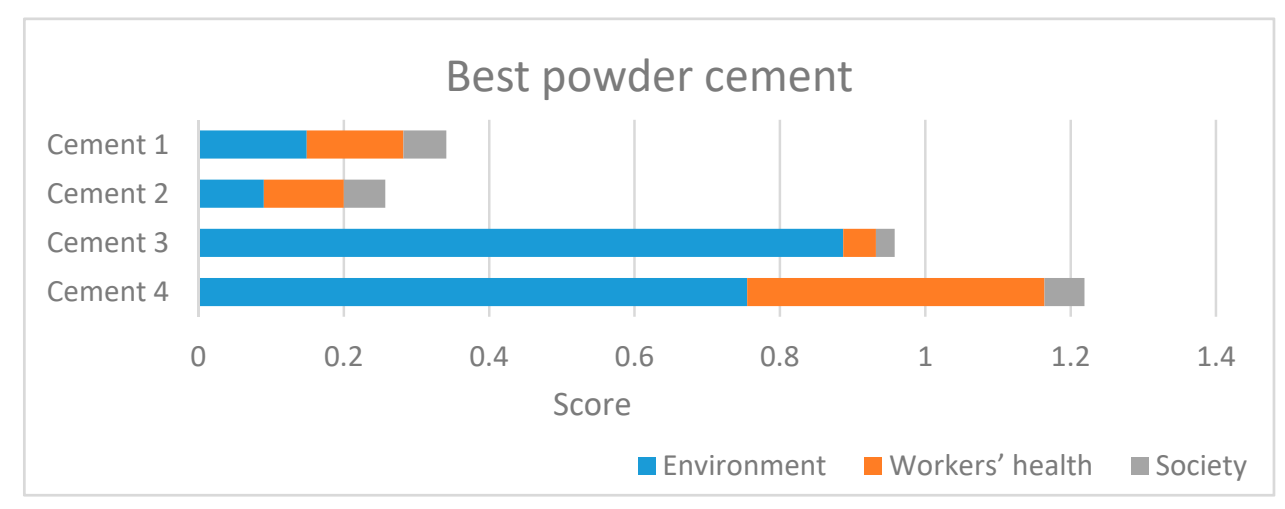

Figure 6. Level I: comparison between cement powders.

Cement 4 is the most sustainable, and its performance is affected by the workers' health criterion. Indeed, this contribution is 0.409 , more than $33.4 \%$ of the overall result, and considerably more than 
the workers' health contribution for the other cements (Figure 4). The results highlight the importance of considering more criteria in the analysis:

- Considering only environment (blue lines), cement 3 would be the best;

- Considering only socio-economic (green lines) results, cement 2 would be the best.

The AHP analysis ensured a good compromise between the three criteria (environment, workers' health and society) applied on the cement production of four Italian companies, which are already placed at a high level in terms of technological and procedural innovation [49].

As it can be observed from all previous analyses, the results obtained from the AHP analysis could be useful to support the process of deciding the "best option", because it allows a comprehensive, critical and unbiased analysis, which could be efficiently replicated at different level [50] in public bids.

\section{Conclusions}

Within the framework of efforts to find a compromise between economic growth and need to protect environment, the European Union has set targets for reducing greenhouse emissions, increasing energy efficiency, promoting use of renewable resources and reducing waste production. The environment is only one of the aspects to be considered in the decision phases, because the design choices involve multiple aspects ranging from legislative to technical-structural issues, from purely economic to human health criteria.

In this sense, the use of multi-criteria decision-making methods can overcome the limits of traditional decision-making approaches that lead one to overlook certain performances or not to give correct importance to others. These methods provide support to those who should make choices, requiring simple tasks in order to reach an objectively valid and unbiased choice.

This paper presents an application of the Analytic Hierarchy Process on four different cement powders produced by Italian companies. The method complies with objective of evaluating various options according to multiple and often conflicting features: it consists of pairwise comparisons between all considered parameters, which are sorted by non-dimensional values. The analysis consists of four levels: (1) the level I, which coincides with overall "goal" of the study: the best cement; (2) the level II, which considers environment, human health and socio-economic aspects; (3) the level III, which includes eight sub-criteria of level 2; (4) the level IV, which consists of 15 numerical sub-criteria of level 3.

The presented analysis allows comparing the overall sustainability of $1 \mathrm{Mg}$ of 32.5 grade cement produced at four different plants. The AHP study demonstrates that considering only environmental issues, cement 3 would be the best; considering only socio-economical results, cement 2 would be the best, while assessing the whole sustainability of each cement, cement 4 is the best. This shows that it is incorrect to consider only one indicator to select the best material among several alternatives, mostly when workers' health is considered. This result is paramount because the growing attention for sustainable construction issues needs for a comprehensive, simple and versatile methodology to be applied at different level in public bids.

Author Contributions: Paola Di Mascio and Laura Moretti conceived and designed the study; Simona Bellagamba performed the multicriteria analysis and analyzed the data; Paola Di Mascio and Laura Moretti wrote the paper.

Conflicts of Interest: The authors declare no conflict of interest.

\section{References}

1. United Nations Office for Project Services (UNOPS). Balancing Social, Environmental and Economic Considerations in Procurement; Supplement to the 2012 Annual Statistical Report on United Nations Procurement; United Nations Office for Project Services: Copenhagen, Denmark, 2013.

2. European Union. Treaty of Amsterdam Amending the Treaty of the European Union, the Treaties Establishing the European Communities and Certain Related Acts; European Union: Amsterdam, The Netherlands, 1997. 
3. Sychrová, L. Evaluation of approaches using the product lifecycle. Econ. Manag. 2012, 17, 1479-1483. [CrossRef]

4. Birou, L.M.; Fawcett, S.E.; Magnan, G.M. The Product Life Cycle: A tool for Functional Strategic Alignment. J. Supply Chain Manag. 1998, 34, 37-52. [CrossRef]

5. European Commission. Green Paper on the Modernization of EU Public Procurement Policy towards a More Efficient European Procurement Market; European Commission: Brussels, Belgium, 2011.

6. Fuentes-Barges, J.L.; González-Cruz, C.; González-Gaya, C. Environmental Criteria in the Spanish Public Works Procurement Process. Int. J. Environ. Res. Public Health 2017, 14, 204. [CrossRef] [PubMed]

7. European Commission. Buying Green! A Handbook on Green Public Procurement, 3rd ed.; European Commission: Brussels, Belgium, 2016.

8. Miccoli, S.; Finucci, F.; Murro, R. The Evaluation of Architectural Quality Design. In Proceedings of the International Multidisciplinary Scientific Conferences on Social Sciences and Arts, Albena, Bulgaria, 2-7 September 2014; pp. 1023-1029.

9. International Organization for Standardization (ISO). ISO 14041:1998. Environmental Management-Life Cycle Assessment_-Goal and Scope Definition and Inventory Analysis; International Organization for Standardization (ISO): Geneva, Switzerland, 1998.

10. International Organization for Standardization (ISO). ISO 14043:2000. Environmental Management-Life Cycle Assessment - Life Cycle Interpretation; International Organization for Standardization (ISO): Geneva, Switzerland, 2000.

11. International Organization for Standardization (ISO). ISO 14040:2006. Environmental Management-Life Cycle Assessment_-Principles and Framework; International Organization for Standardization (ISO): Geneva, Switzerland, 2006.

12. International Organization for Standardization (ISO). ISO 14044:2006. Environmental Management-Life Cycle Assessment-Requirements and Guidelines; International Organization for Standardization (ISO): Geneva, Switzerland, 2006.

13. International Organization for Standardization (ISO). ISO 14042:2006. Environmental Management-Life Cycle Assessment_Life Cycle Impact Assessment; International Organization for Standardization (ISO): Geneva, Switzerland, 2006.

14. Moretti, L.; Caro, S. Critical analysis of the Life Cycle Assessment of the Italian cement industry. J. Clean. Prod. 2017, 152, 198-210. [CrossRef]

15. Miccoli, S.; Finucci, F.; Murro, R. Assessing Project Quality: A Multidimensional Approach. Adv. Mater. Res. 2014, 1030-1032, 2519-2522. [CrossRef]

16. Leopold, L.; Clarke, F.; Hanshaw, B.; Balslay, J. A Procedure for Evaluating Environmental Impact; US Geological Survey Circular 645: Washington, DC, USA, 1971.

17. Dee, N.; Baker, J.; Drobny, N.; Duke, K.; Fahringer, D. Environmental Evaluation System for Water Resource Planning (to Bureau of Reclamation, U.S. Department of Interior); Battelle Columbus Laboratory: Columbus, $\mathrm{OH}$, USA, 1972; 188p.

18. Dee, N.; Baker, J.; Drobny, N.; Duke, K.; Whitman, I.; Fahringer, D. An environmental evaluation system for water resource planning. Water Resour. Res. 1973, 9, 523-535. [CrossRef]

19. Miccoli, S.; Finucci, F.; Murro, R. A Direct Deliberative Evaluation Procedure to Choose a Project for Via Giulia in Rome. Pollack Period. Int. J. Eng. Inf. Sci. 2015, 10, 143-153. [CrossRef]

20. Loprencipe, G.; Pantuso, A.; Di Mascio, P. Sustainable Pavement Management System in Urban Areas Considering the Vehicle Operating Costs. Sustainability 2017, 9, 453. [CrossRef]

21. Crow, J.M. The concrete conundrum. Chem. World 2008, 5, 62-66.

22. Bonin, G.; Cantisani, G.; Loprencipe, G.; Ranzo, A. Dynamic effects in concrete airport pavement joints. Ind. Ital. Cem. 2007, 77, 590-607.

23. Moretti, L.; Cantisani, G.; Di Mascio, P.; Caro, S. Technical and economic evaluation of lighting and pavement in Italian road tunnels. Tunn. Undergr. Space Technol. 2017, 65, 42-52. [CrossRef]

24. Loprencipe, G.; Cantisani, G. Evaluation methods for improving surface geometry of concrete floors: A case study. Case Stud. Struct. Eng. 2015, 4, 14-25. [CrossRef]

25. Moretti, L.; Mandrone, V.; D'Andrea, A.; Caro, S. Comparative "from cradle to gate" life cycle assessments of Hot Mix Asphalt (HMA) materials. Sustainability 2017, 9, 400. [CrossRef] 
26. Moretti, L. Technical and economic sustainability of concrete pavements. Mod. Appl. Sci. 2014, 8, 1-9. [CrossRef]

27. International Organization for Standardization (ISO). ISO 14025:2006. Environmental Labels and Declarations-Type III Environmental Declarations_Principles and Procedures; International Organization for Standardization (ISO): Geneva, Switzerland, 2006.

28. European Committee for Standardization. EN 197:2011. Cement. Composition, Specifications and Conformity Criteria for Common Cements; European Committee for Standardization: Brussels, Belgium, 2013.

29. European Committee for Standardization. EN 15804:2013. Sustainability of Construction Works-Environmental Product Declarations - Core Rules for the Product Category of Construction Products; European Committee for Standardization: Brussels, Belgium, 2013.

30. Mahmoudi, S.; Ghasemi, F.; Mohammadfam, I.; Soleimani, E. Framework for Continuous Assessment and Improvement of Occupational Health and Safety Issues in Construction Companies. Saf. Health Work 2014, 5, 125-130. [CrossRef] [PubMed]

31. Parlamento Italiano. Decreto Legislativo n.81/2008. Attuazione Dell'articolo 1 della Legge 3 Agosto 2007, n. 123 in Materia di Tutela della Salute e della Sicurezza nei Luoghi di Lavoro; Parlamento Italiano: Rome, Italy, 2008.

32. European Commission. Directive 2003/53/EC of the European Parliament and of the Council of 18 June 2003 Amending for the 26th Time Council Directive 76/769/EEC Relating to Restrictions on the Marketing and Use of Certain Dangerous Substances and Preparations (Nonylphenol, Ethoxylate and Cement); European Commission: Brussels, Belgium, 2003.

33. Associazione Italiana Tecnico Economica Cemento (AITEC). Annual Report 2009; Associazione Italiana Tecnico Economica Cemento (AITEC): Rome, Italy, 2010.

34. American Conference of Governmental Industrial Hygienists (ACGIH). Silica, Crystalline-Quartz. In The Documentation of the Threshold Limit Values and Biological Exposure Indices, 7th ed.; American Conference of Governmental Industrial Hygienists: Cincinnati, OH, USA, 2010.

35. Ispettorato Medico Centrale. Circolare 737 del 03.12.1991; Ispettorato Medico Centrale: Rome, Italy, 1991.

36. Saaty, R.W. The analytic hierarchy process-what it is and how it is used. Math. Model. 1987, 9, 161-176. [CrossRef]

37. Cavallo, B.; D’Apuzzo, L. A general unified framework for pairwise comparison matrices in multicriterial methods. Int. J. Intell. Syst. 2009, 24, 377-398. [CrossRef]

38. Kennet, A. Social Choice and Individual Values; Wiley: New York, NY, USA, 1951.

39. Aruldoss, M.; Lakshmi, T.M.; Venkatesan, V.P. A Survey on Multi Criteria Decision Making Methods and Its Applications. Am. J. Inf. Syst. 2013, 1, 31-43.

40. Sana, S.; Bhat, G.A.; Balkhi, H.M. Health Risks Associated With Workers in Cement Factories. Int. J. Sci. Res. Publ. 2013, 3, 1-5.

41. Associazione Italiana Tecnico Economica Cemento (AITEC). Environmental Product Declaration: Average Italian Cement. Registration Number S-P-00880. Rome, Italy, 2016. Available online: http:// gryphon.environdec.com/data/files/6/11845/epd880it\%20Average\%20Italian\%20cement.pdf (accessed on 15 January 2017).

42. European Commission. Best Available Techniques (BAT) Reference Document for the Production of Cement, Lime and Magnesium Oxide: Industrial Emissions Directive 2010/75/EU: (Integrated Pollution Prevention and Control); European Commission: Brussels, Belgium, 2013.

43. Schneider, M.; Romer, M.; Tschudin, M.; Bolio, H. Sustainable Cement Production—Present and Future. Cem. Concr. Res. 2011, 41, 642-650. [CrossRef]

44. European Community. Handbook for Implementation of EU Environmental Legislation; European Commission: Brussels, Belgium, 2008.

45. Canfeng, Z.; Shujie, Y.; Dong, L. Comprehensive Control of the Noise Occupational Hazard in Cement Plant. Procedia Eng. 2012, 43, 186-190. [CrossRef]

46. Hernández-Gaytán, S.; Santos-Burgoa, C.; Becker-Meyer, J.P.; Macías-Carrillo, C.; López-Cervantes, M. Prevalence of hearing loss and correlated factors in a cement plant. Salud Publica Mex. 2000, 42, 106-111. [CrossRef] [PubMed]

47. Associazione Italiana Tecnico Economica Cemento (AITEC). Life Cycle Assessment of Italian Gray Cement; Internal Document; Associazione Italiana Tecnico Economica Cemento: Rome, Italy, 2016. 
48. Shafeek, A.M.; Salah, H.; Shebata, N.; Saddek, A.B. The impact of cooling water types on the cement clinker properties. Egypt. J. Pet. 2017. [CrossRef]

49. Moretti, L.; Cantisani, G.; Di Mascio, P. Management of road tunnels: Construction, maintenance and lighting costs. Tunn. Undergr. Space Technol. 2016, 51, 84-89. [CrossRef]

50. Loprencipe, G.; Cantisani, G.; Di Mascio, P. Global assessment method of road distresses. Life-cycle of structural systems: Design, assessment, maintenance and management. In Proceedings of the 4th International Symposium on Life-Cycle Civil Engineering, (IALCCE 2014), Tokyo, Japan, 16-19 November 2014.

(C) 2017 by the authors. Licensee MDPI, Basel, Switzerland. This article is an open access article distributed under the terms and conditions of the Creative Commons Attribution (CC BY) license (http:/ / creativecommons.org/licenses/by/4.0/). 